\title{
Behaviour and physiological responses during prone and supine sleep in early infancy
}

\author{
B T Skadberg, T Markestad
}

\begin{abstract}
Aims-To study the effect of prone and supine sleep on infant behaviour, peripheral skin temperature, and cardiorespiratory parameters to aid understanding of why prone sleeping is associated with an increased risk of sudden infant death syndrome.

Methods-Of 33 enrolled infants, 32 were studied at 2.5 and 28 at 5 months of age. A computer aided multichannel system was used for polysomnographic recordings. Behaviour was charted separately. Results-Prone REM (active) sleep was associated with lower frequencies of short arousals, body movements and sighs, and a shorter duration of apnoeas than supine REM sleep at both ages. At 2.5 months there were less frequent episodes of periodic breathing during prone sleep in nonREM (quiet) and REM sleep. Heart rate and peripheral skin temperature were higher in the prone position during both sleep states at both ages.

Conclusions-The observation of decreased variation in behaviour and respiratory pattern, increased heart rate, and increased peripheral skin temperature during prone compared with supine sleep may indicate that young infants are less able to maintain adequate respiratory and metabolic homoeostasis during prone sleep.

(Arch Dis Child 1997;76:320-324)
\end{abstract}

Keywords: behaviour; sudden infant death syndrome; sleeping position

Prone sleeping, overwrapping, heating of the bedroom, and other infant care practices which may increase body temperature are reported risk factors for sudden infant death syndrome (SIDS).$^{1-4}$ There seems to be a causal relation between prone sleeping and SIDS, but the terminal, pathophysiological mechanisms causing death are largely unknown. Lack of a normal arousal response ${ }^{5}$ or suffocation due to airway obstruction or rebreathing of carbon dioxide from a face down position ${ }^{6-10}$ have been suggested as contributory mechanisms. Although epidemiological studies have shown that there is an association between overwrapping and increased environmental temperature, and SIDS, the mechanisms of interaction are not understood. ${ }^{2}$ The issue is complicated further as overheating seems to be a risk factor particularly or exclusively for infants sleeping prone. $^{24}$
The purpose of the present study was to compare supine and prone sleeping in early infancy with respect to sleep related behaviour, peripheral body temperature, and cardiorespiratory responses in a warm environment to add understanding to why prone sleeping is a major risk factor for SIDS.

\section{Subjects and methods}

SUBJECTS

Thirty three infants ( 17 girls and 16 boys) were recruited for an overnight sleep study. Only term infants (at least 37 weeks' postconceptional age) without prenatal or perinatal complications were included. No infant with a positive history of family diseases, apparently life threatening events, or cases of SIDS in siblings was allowed. The mean birth weight was $3631 \mathrm{~g}$ (range 2870-4840 g) and all infants were healthy at the time of the study.

A questionnaire containing information on infant care practices such as feeding, preferred sleeping position, sleep environment, weight gain, and psychomotor development in relation to the ability to move was completed by the parents at the time of each study.

Informed, written consent was obtained from the parents of all infants and the study was approved by the regional committee on medical research ethics.

\section{STUDY CONDITIONS}

The infants were admitted early in the evening for a 12 hour polysomnographic recording of sleep related behaviour. They were all fed before and often during the electrode preparation. Their normal feeding schedule was followed during the evening and they were further fed in the middle of the night before a change in sleeping position was made. After the evening feed the infants were put to sleep in the supine position by their mother. Comforters and 'cosies' were allowed while falling asleep, but were removed thereafter. The room was darkened and the mother stayed with her infant until he or she fell asleep if this was the routine at home; otherwise the infant was left alone with the doctor. The study conditions were identical at 2.5 and 5 months.

The infants were studied in an infant bed (with bars as side walls) with a firm foam rubber mattress (normal hospital cot mattress; polyurethane $30 \mathrm{~N}, 9.5 \mathrm{~cm}$ thick) lined with a thin blanket. All were dressed in a diaper and two shirts and covered with a duvet (polyester fibre quilt, $145 \times 115 \mathrm{~cm}$ with a cotton quilt cover, total weight $1300 \mathrm{~g}$, total tog value 13). ${ }^{11}$ Light clothing $(2.5 \operatorname{tog})^{11}$ was chosen to ease 
the nursing of the infant and the supervision of the sensors, and the room temperature was kept at $23^{\circ} \mathrm{C}\left( \pm 0.5^{\circ} \mathrm{C}\right)$ to obtain an environmental temperature close to the corresponding thermoneutral range. ${ }^{12}$ The duvet covered the lower part of the infants' body (mid thorax).

The overnight sleep was divided into two equal periods of prone and supine sleep. The initial position was chosen at random using the sealed envelope method and during the first non-REM (quiet sleep) interval after falling asleep, half the infants were turned to the prone position according to the randomisation. All infants were moved to the opposite position midway through the study after being fed. The first undisturbed sleep cycle of non-REM and REM (active) sleep in either body position was used for the analyses. The additional sleep cycles in each body position were used for specific testing of infants' arousability and carbon dioxide rebreathing.

METHODS

Polysomnography

A computer aided multichannel system with the operating CARDAS software (Computer Aided Record Display and Analysis Systems) and the Oxcams/Pi Logic IMS-2000 multichannel monitor (Oxcams/Pi Logic Ltd, Dyfed) were used for the polysomnographic recordings. For each infant the sleep variables recorded included two electroencephalographic derivations (C3-A2, C4-A1; EEG), two electro-occulographic derivations (ROC/ A1, LOC/A2; EOG), and a chin electromyogram (EMG). The physiological parameters recorded continuously were as follows: an electrocardiogram (ECG, three leads placed on the upper part of the trunk); thoracic and abdominal respiratory movements (strain gauge, Sensorband, Mediplus AB, Malmø, Sweden); peripheral skin temperature (left foot, Skin Surface Temp xHH-10005-x, Ellab as, Denmark); oxygen saturation (right foot, oxygen trend curve, pulse rate, and pulse waveform; Ohmeda Biox 3700, $50 \mathrm{~Hz}$ fast mode, data average time 3 seconds, update interval 0.375 seconds, Ohmeda Medical System Division, Louisville, CO, USA); body movements (pressure sensitive pad placed under the blanket on the mattress; Pad-HF, B8208, Pi Logic Ltd); and sound (microphone placed on the mattress $3 \mathrm{~cm}$ to the left or right of the nose and mouth in prone or supine face to side position, on the neckband of the shirt in the supine face up position, Sound, B8202, Pi Logic Ltd).

Attempts to estimate the core temperature were abandoned because a method for central skin temperature (Thermistor Zeal, Pi Logic Ltd) did not correlate sufficiently with rectal temperature and rectal monitoring was unsuccessful in a pilot project as it interfered with sleep behaviour. It has been shown that the peripheral skin and rectal temperatures change together, and that changes in skin temperature fluctuate less throughout the night than the core temperature. ${ }^{13}$ Furthermore, on warming peripheral vasodilatation and subsequent increases in peripheral body temperature occur to increase the heat loss. ${ }^{1}$ We therefore found it acceptable to record the peripheral skin temperature alone to evaluate the thermal stress. Attempts to measure the air flow by thermistors were abandoned mainly because sleep behaviour was disturbed, especially in the prone position, but also because of low sensor sensitivity in the younger infants (EdenTech infant airflow sensor, EdenTech Corp, $\mathrm{MN}$, USA).

\section{Recorded responses}

Sleep states were defined according to behavioural, EEG, EOG, and EMG criteria recommended by other investigators. ${ }^{14-16}$ Each minute of the recording was coded as nonREM sleep, REM sleep, indeterminate sleep, or awakening. Non-REM or quiet sleep was defined as: eyes closed with no eye movements; no body movements except occasional generalised startles; a high voltage and slow wave pattern or sleep spindles on EEG; resting muscle tone on EMG; and decreased heart and respiratory rates. REM or active sleep was defined as: visible eye movements under the eyelids independent of facial or gross body movements; frequent small movements of the head, face, and limbs; a low voltage and fast desynchronised pattern on EEG; muscle atonia on EMG; and rapid and irregular heart and respiratory rates. Periods of sleep not meeting these criteria were classified as indeterminate sleep and periods with open eyes, body movements, and vocalisation were classified as awake. Behaviour was charted separately.

The sleep periods scored from the polysomnograph were further compared with the behavioural observations and only periods of sleep in agreement with respect to states were carefully scrutinised for technical problems such as loose probes, artefact time not exceeding 15 seconds, and agreement of heart and pulse rates. Only unblemished data were used for the analysis of physiological responses. If the arousals lasted longer than 15 seconds the sequence was excluded from the analysis, as were intervals of sleep in which the heart rate from the ECG tracing differed with more than an average of 3 beats/minute from the pulse rate recorded by the pulse oximeter.

Only non-REM and REM sleep were considered in this study. We did not differentiate between sleep stages during non-REM sleep as there is a considerable within and between subject variability in characteristics used for a more detailed sleep staging in early infancy. ${ }^{16}$ Furthermore, as unfamiliar sleep environments, temperature differences, a change in daily care giving practices, and sleeping position may all affect sleep and waking behaviour, ${ }^{17}$ we found it inappropriate to evaluate and claim normality of sleep parameters such as total sleep time and time spent in different sleep states.

All parameters of the polysomnographic recordings were directly and continuously stored on a hard disk either as trend curves or as digitised, raw signals. The intervals used for further analysis were all chosen according to criteria given in the protocol before the study was initiated. 
Table 1 Characteristics of the infants studied at 2.5 and 5 months of age

\begin{tabular}{lll}
\hline & 2.5 months $(n=32)$ & 5 months $(n=28)$ \\
\hline No of girls/boys & $16 / 16$ & $14 / 14$ \\
Mean (SD) weight (g) & $5845(696)$ & $7497(833)$ \\
Breast fed & 28 & 21 \\
No sleeping in bed with parents & 0 & 1 \\
No with supine preferred position & 25 & 28 \\
No with side or supine preferred position & 3 & 0 \\
No with side preferred position & 4 & 0 \\
\hline
\end{tabular}

Respiratory rate and respiratory movements were estimated from the thoracic or abdominal amplitude on the pneumogram, or both.

A sigh was defined as an isolated and sudden change in the amplitude of either the thoracic or abdominal respiratory channel. A movement of the head or extremities was defined by artefacts in a limited number of channels with an increase in the amplitude of the activity channel, whereas arousals caused artefacts in most channels. Arousals were further subdivided into short arousals - that is, body movements lasting between 3 and 15 seconds without changes in EEG - and longer arousals lasting more than 15 seconds, often associated with changes in EEG and subsequent awakening.

Periodic breathing was defined by the succession of more than two apnoeas longer than 3 seconds separated from each other by less than 20 seconds of breathing movements.

An apnoea was measured from the end of inspiration in the last breath before to the end of inspiration in the first breath after the apnoea. The measurement was performed either in the thoracic or abdominal channel depending on the technical quality of the signals. Apnoeas lasting 3 seconds or longer were recorded. The apnoeas were divided into two subgroups depending on the duration: from 3 to 10 and from 11 seconds or longer.

The ECG was stored continuously both as single heart beats and as a trend curve. The heart rate could therefore be counted manually despite artefacts from arousals and body movements.

As the signals of the pulse oximeter are sensitive to body movements, it was often difficult to interpret the oxygen saturation during and immediately after arousals and body movements. Only intervals with appropriate pulse waves were used for further analysis.

\section{Analysis}

The data were analysed with SPSS for MS Windows Release 6.0. Analyses were limited to the first sleep cycle in each body position. The paired $t$ test for dependent samples was used for statistical analyses. As the polysomnographic recordings were continuously correlated with behavioural observations the data were not analysed blindly with respect to sleeping position. The possibility of bias was minimised by strict a priori criteria and the use of computer generated polysomnographic results.

\section{Results}

Of the 33 infants enrolled in the study, 32 were recorded in both supine and prone sleeping positions at 2.5 months and 28 at 5 months. Two infants (one at each age) were excluded because of illness and two were withdrawn at 5 months by the parents. At 5 months two infants were excluded from the analyses because they did not accept the prone position. Hence 27 infants were studied in both positions at both ages.

Table 1 lists the characteristics of the infants studied at least once; these did not differ from those who could not be tested. The mean weight was at the 50th centile for Norwegian infants. Supine was the dominant sleeping position, but all infants were regularly put into the prone position while awake to increase their extensor muscle strength.

Approximately 50 minutes of adequate recordings were obtained for prone and supine sleep at 2.5 and 5 months (table 2). For REM sleep there were more frequent short arousals, body movements, and sighs during supine than during prone sleep for both ages, and at 2.5 months there were more episodes of periodic breathing in supine non-REM and REM sleep (table 2). For both sleep states and ages the frequency of sigh related apnoeas and their duration were longer during supine sleep. For a set of other behavioural parameters there was no significant difference between prone and supine sleep (table 2). No or only minimal changes in heart rate and oxygen saturation were observed subsequent to apnoeas lasting less than 5 seconds. A temporary decrease in heart rate occurred in $15 \%$ of apnoeas lasting longer than 5 seconds and in half of these instances the oxygen saturation also decreased. The longest apnoea lasted 15 seconds, the maximum decrease in heart rate was $35 \%$, and the maximum decrease in oxygen saturation was $11 \%$.

Heart rates and peripheral skin temperatures were higher in the prone than in the supine position during both non-REM and REM sleep at 2.5 and 5 months, but there was no significant difference between the two positions with respect to respiratory rate or oxygen saturation for either sleep state or age (table 3 ).

For both body positions the heart rate was significantly higher during REM than nonREM sleep at both ages $(p<0.001)$, whereas the respiratory rate was higher and oxygen saturation lower during REM sleep at 2.5 months ( $\mathrm{p}<0.05$ and $\mathrm{p}<0.01$, respectively) (table 3). The peripheral skin temperature did not vary significantly with sleep state, but decreased after body movements and arousals in both body positions as the movements of the duvet allowed the entry of fresh air close to the body. The skin temperature for both sleep states tended to be lower at 5 than at 2.5 months, and the heart and respiratory rates decreased significantly with increasing age $(p$ $\leqslant 0.02$ ) (table 3).

\section{Discussion}

In the present study prone and supine sleep differed in that prone sleep was associated with less variation in behaviour, such as fewer body movements, fewer short arousals, sighs and episodes of periodic breathing, and a shorter 
duration of apnoeas after sighs. In spite of less behavioural variability the heart rates and peripheral body temperatures were higher during prone sleep, and the differences were more pronounced during active than during quiet sleep.

The sleep behaviour found in this study confirms the results reported for healthy newborn infants by Douthitt and Brackbill more than 20 years ago, ${ }^{18}$ and those reported in 1993 in 3 month old infants by Kahn et al. ${ }^{19}$ As the goal in the past was to promote sleep, less motor activity and awakenings during prone sleep were interpreted as favourable. We suggest, however, as have others, ${ }^{20}$ that the greater variation in behaviour during supine sleep may protect the infant from SIDS. Indeed, studies on cosleeping with the mother have shown that more frequent arousals, shifts in sleep states, and less time spent in quiet sleep may be the normal behaviour of young infants. ${ }^{20}$ This notion is further supported by the suggestion that impaired arousal responsiveness is necessary for SIDS to occur. ${ }^{52}$ As infants are less able to respond adequately with arousal to internal stimuli in deeper (stage 3-4) than in lighter sleep (stage 1-2), ${ }^{522}$ we also speculate that habitual prone sleeping may accelerate the maturation of sleep - that is, prolonged uninterrupted sleep - before arousal mechanisms in response to cardiorespiratory or thermal stimuli are fully developed. More frequent sighs and longer duration of apnoeas after the sighs, as was seen in supine sleep in our study, may also represent improved adaptive behaviour similar to that of increased arousals. The apnoeas were not associated with untoward physiological responses and may simply represent a natural pause after improved ventilation.

Thermal stress from heavy wrapping and a warm sleeping environment has been identified as a risk factor for SIDS, especially in infants more than 10 weeks old sleeping prone. ${ }^{24}$ Although not fully understood, increased body temperature has been suggested to interfere with other physiological processes such as peripheral and central regulation of respiratory drive. ${ }^{523-30}$ The recorded skin temperatures were higher in the present than in one previous study, ${ }^{30}$ probably reflecting a higher insulating effect of the duvet (estimated tog value 13) compared with the double blanket used in the referred study (estimated tog value $2-3$ ). The higher peripheral skin temperatures while

Table 2 Sleep behaviour during prone and supine sleep at 2.5 and 5 months

\begin{tabular}{|c|c|c|c|c|c|c|c|c|c|c|}
\hline \multirow[b]{2}{*}{ Sleep parameter } & \multicolumn{5}{|c|}{2.5 months ( $n=32$ pairs) } & \multicolumn{5}{|c|}{5 months ( $n=28$ pairs) } \\
\hline & Prone & Supine & $D B M$ & $S E$ & $p$ Value & Prone & Supine & $D B M$ & $S E$ & $p$ Value \\
\hline Total analysed sleep time (min) & 51.8 & 51.6 & 0.2 & 2.7 & 0.9 & 45.9 & 49.8 & 3.9 & 3.1 & 0.2 \\
\hline Analysed non-REM sleep (min) & 28.3 & 28.3 & 0.3 & 1.7 & 0.9 & 30.5 & 31.3 & 0.8 & 2.1 & 0.7 \\
\hline Analysed REM sleep (min) & 23.6 & 23.7 & 0.1 & 2.0 & 1.0 & 15.8 & 18.5 & 2.7 & 1.9 & 0.15 \\
\hline No of short arousals, non-REM & 0.3 & 0.2 & 0.1 & 0.2 & 0.6 & 0.8 & 0.6 & 0.2 & 0.2 & 0.6 \\
\hline No of short arousals, REM & 3.2 & 4.6 & 1.4 & 0.7 & 0.06 & 1.0 & 1.8 & 0.8 & 0.3 & 0.01 \\
\hline No of body movements, non-REM & 0.7 & 0.6 & 0.1 & 0.2 & 0.8 & 2.0 & 1.1 & 0.9 & 0.4 & 0.06 \\
\hline No of body movements, REM & 5.3 & 7.5 & 2.2 & 0.8 & 0.01 & 3.5 & 5.3 & 1.8 & 0.8 & 0.04 \\
\hline No of sighs, non-REM & 1.4 & 1.2 & 0.2 & 0.4 & 0.7 & 1.5 & 2.4 & 0.9 & 0.4 & 0.05 \\
\hline No of sighs, REM & 8.9 & 14.1 & 5.2 & 1.4 & $<0.01$ & 5.2 & 7.4 & 2.3 & 0.8 & 0.01 \\
\hline No of sighs with apnoea, non-REM & 2.0 & 3.0 & 1.0 & 0.3 & $<0.01$ & 2.4 & 4.1 & 1.7 & 0.6 & $<0.01$ \\
\hline No of sighs with apnoea, REM & 2.1 & 2.1 & 0.03 & 0.4 & 0.9 & 1.5 & 3.1 & 1.6 & 0.8 & 0.05 \\
\hline $\begin{array}{l}\text { Post-sigh apnoea duration, } \\
\text { non-REM (sec) }\end{array}$ & 8.0 & 10.5 & 2.5 & 0.8 & $<0.01$ & 2.1 & 7.9 & 5.8 & 1.0 & $<0.01$ \\
\hline $\begin{array}{l}\text { Post-sigh apnoea duration, REM } \\
\quad(\mathrm{sec})\end{array}$ & 5.9 & 7.7 & 1.8 & 0.8 & 0.03 & 1.5 & 7.3 & 5.8 & 0.8 & $<0.01$ \\
\hline No of apnoeas 3-10 sec, non-REM & 0.43 & 0.37 & 0.06 & 0.2 & 0.8 & 0.6 & 0.1 & 0.5 & 0.2 & 0.04 \\
\hline No of apnoeas 3-10 sec, REM & 14 & 18 & 4 & 2.6 & 0.1 & 13 & 12 & 1 & 2.3 & 0.6 \\
\hline No of apnoeas $>10 \mathrm{sec}$, non-REM & 0.03 & 0.0 & 0.3 & 0.03 & 0.3 & 0.0 & 0.0 & 0.0 & 0.0 & - \\
\hline No of apnoeas $>10 \mathrm{sec}, \mathrm{REM}$ & 0.06 & 0.03 & 0.03 & 0.07 & 0.7 & 0.1 & 0.1 & 0.03 & 0.08 & 0.6 \\
\hline $\begin{array}{l}\text { No of episodes of periodic breathing, } \\
\text { non-REM }\end{array}$ & 0.3 & 0.5 & 0.2 & 0.1 & 0.07 & 0.2 & 0.3 & 0.1 & 0.1 & 0.54 \\
\hline $\begin{array}{l}\text { No of episodes of periodic breathing, } \\
\text { REM }\end{array}$ & 0.5 & 0.8 & 0.3 & 0.1 & 0.01 & 0.4 & 0.4 & 0.0 & 0.1 & 1.0 \\
\hline
\end{tabular}

$\mathrm{DBM}=$ differences between means; $\mathrm{SE}=$ standard error of difference between means. Levels of significance between prone and supine sleep according to respective $\mathrm{p}$ values.

Table 3 Mean, differences between means (DBM), and standard error of differences between means (SE) of physiological parameters during prone and supine non-REM and REM sleep at 2.5 and 5 months of age

\begin{tabular}{|c|c|c|c|c|c|c|c|c|c|c|}
\hline \multirow[b]{2}{*}{ Sleep parameter } & \multicolumn{5}{|c|}{2.5 months ( $n=32$ pairs) } & \multicolumn{5}{|c|}{5 months ( $n=28$ pairs) } \\
\hline & Prone & Supine & $D B M$ & $S E$ & $p$ Value & Prone & Supine & $D B M$ & $S E$ & p Value \\
\hline Heart rate (beats/min), non-REM & 125.1 & 118.9 & 6.2 & 1.1 & $<0.001$ & 118.8 & 114.1 & 4.3 & 1.0 & $<0.001$ \\
\hline Heart rate (beats/min), REM & 129.1 & 124.4 & 4.7 & 1.2 & 0.001 & 124.2 & 120.1 & 4.1 & 0.8 & $<0.001$ \\
\hline $\begin{array}{l}\text { Respiratory rate (breaths/min), } \\
\text { non-REM }\end{array}$ & 28.4 & 27.7 & 0.7 & 0.7 & 0.3 & 25.2 & 24.6 & 0.4 & 0.7 & 0.4 \\
\hline Respiratory rate (breaths/min), REM & 29.5 & 28.8 & 0.7 & 0.8 & 0.4 & 25.2 & 24.7 & 0.5 & 0.8 & 0.6 \\
\hline Oxygen saturation (\%), non-REM & 99.2 & 99.3 & 0.1 & 0.2 & 0.7 & 99.0 & 98.8 & 0.2 & 0.1 & 0.2 \\
\hline Oxygen saturation (\%), REM & 98.7 & 98.6 & 0.1 & 0.1 & 0.5 & 98.7 & 98.7 & 0.0 & 0.0 & - \\
\hline $\begin{array}{l}\text { Peripheral skin temperature, }\left({ }^{\circ} \mathrm{C}\right) \text {, } \\
\text { non-REM } \\
\text { Peripheral skin temperature }\left({ }^{\circ} \mathrm{C}\right) \text {, }\end{array}$ & 36.3 & 36.0 & 0.3 & 0.1 & 0.04 & 36.1 & 35.8 & 0.3 & 0.1 & $<0.01$ \\
\hline REM & 36.3 & 35.9 & 0.4 & 0.1 & $<0.001$ & 36.1 & 35.7 & 0.4 & 0.1 & 0.01 \\
\hline
\end{tabular}

Levels of significance between body positions during non-REM and REM sleep according to respective p values. 
prone may be interpreted as an increased risk of overheating in this position, either as a result of reduced heat loss or increased metabolic rate due to, for example, added respiratory effort. Compared with the supine position, the prone position both reduces heat loss by increasing the fraction of the body surface in contact with the mattress, ${ }^{1}$ and, as suggested in the present study, by less arousals and body movements with subsequent reduced circulation of fresh air around the body. In heavily dressed infants most of the heat loss occurs from the head and face, ${ }^{131}{ }^{32}$ and the face has been shown to have unique thermoregulatory functions. ${ }^{33}{ }^{34}$ Even in the prone face to side position, a smaller fraction of the face is available for heat loss. In addition, the prone position promotes a face down position, increases the risk of slipping under the cover with the head, and renders the infant less able to get the cover off their head, ${ }^{13536}$ (personal observation) which all tend to increase the risk of overheating even further.

Prone infants may be subjected to an increased concentration of carbon dioxide around the face, with subsequent rebreathing sufficient to stimulate respiration..$^{35}$ It is unlikely, however, that the infants in this study experienced carbon dioxide rebreathing while prone as they were positioned on a firm mattress with the head uncovered and the face turned to the side. ${ }^{35} 3738$ This assumption is further supported by a lack of difference in respiratory rate and oxygen saturation between body positions. The observed increase in heart rate while prone probably resulted from thermal stress, with subsequent vasodilatation and a reflex mediated rise in heart rate.

The prone sleeping position is obviously the major risk factor for SIDS, but the exact mechanism of death remains largely speculative. We suggest that the decreased variation in behaviour and respiratory pattern, and the increased need and probably greater difficulty of getting rid of excess heat in the prone position, may indicate that young infants are at higher risk of respiratory and metabolic strain during prone sleep.

This research was supported by the Norwegian Research Council for Science and the Humanities, the Norwegian SIDS Society, and the local SIDS Society.

1 Nelson EAS, Taylor BJ, Weatherall IL. Sleeping position and infant bedding predispose to hyperthermia and the sudden infant death syndrome. Lancet 1989;i:199-201.

2 Fleming PJ, Gilbert R, Azaz Y, et al. Interaction between bedding and sleeping position in the sudden infant death syndrome: a population based case-control study. $B M \mathcal{F}$ 1990;301:85-9.

3 Mitchell EA, Ford RPK, Taylor BJ, et al. Further evidence supporting a causal relationship between prone sleeping supporting a causal relationship between prone sleeping

4 Ponsonby AL, Dwyer T, Gibbons LE, Cochrane J, You-Gan Ponsonby AL, Dwyer T, Gibbons LE, Cochrane J, You-Gan W. Factors potentiating the risk of sudden infant death syndrome associated

5 Hunt CE. Sudden infant death syndrome. In: Beckman RC, Brouillette RT, Hunt CE, eds. Respiratory control disorders in infants and children. Baltimore: Williams and Wilkins, 1992 190-211.

Abrahamson $\mathrm{H}$. Accidental mechanical suffocation in infants. $\mathcal{F}$ Pediatr 1944;25:404-13.

7 Emery JL, Thornton JA. Effects of obstruction to respiration in infants with particular references to mattresses, pillows, and their coverings. BMF 1968;3:209-13.

8 Wolley JR. Mechanical suffocation during infancy. $\mathcal{F}$ Pediatr 1945;26:72-5.
9 Kemp JS, Kowalski RM, Burch PM, Graham MA, Thach BT. Unintentional suffocation by rebreathing: a death scene and physiologic investigation of a possible cause of sudden infant death. $\mathcal{F}$ Pediatr 1993;122:874-80.

10 Bolton DPG, Taylor BJ, Campbell AJ, Galland BC, Cresswell C. Rebreathing expired gases from bedding. Arch Dis Child 1993;69:187-90.

11 Culow EE. Thermal insulation properties of fabrics. Textiles 1978;1:47-52.

12 Wigfield RE, Fleming PJ, Azaz YEZ, et al. How much wrapping do babies need at night? Arch Dis Child 1993;69:1816 .

13 Wailoo MP, Petersen SA, Whittaker H, Goodenough P. Sleeping body temperatures in 3-4 month old infants. Arch Dis Child 1989;64:596-9.

4 Prechtl HFR. The behavioural states of the newborn infant (a review). Brain Res 1974;76:185-212.

15 Anders T, Embde R, Parmelee A. A manual of standardised terminology, techniques and criteria for scoring of states of sleep and wakefulness in newborn infants. Los Angeles: Brain Information Service/Brain Research Institute, University of California, 1970.

16 Hoppenbrowers T, Hodgeman JE, Kazuko A, Geidel SA, Sterman MB. Sleep and waking states in infancy: normative studies. Sleep 1988;60:387-401.

17 Sostek AM, Anders TF. Effects of varying laboratory conditions on behavioral state organisation in two and eight week old infants. Child Dev 1975;46:871-8.

18 Douthitt TC, Brackbill Y. Differences in sleep, waking and motor activity as a function of prone or supine resting position in the human neonate. Psychophysiology 1972;9:99100 .

19 Kahn A, Grosswasser J, Sottiaux M, Rebuffat E, Franco E, Dramaix M. Prone or supine position and sleep characteristics in infants. Pediatrics 1993;6:1112-5.

20 McKenna JJ, Thoman EB, Anders F, Sadeh A, Schechtman VL, Glotzbach SF. Infant-parent co-sleeping in an evolutionary perspective: implications for understanding infant sleep development and the sudden infant death syndrome. Sleep 1993;16:263-82.

21 Harper RM, Leake B, Hoffman H, et al. Periodicity of sleep states is altered in infants at risk for the sudden infant death syndrome. Science 1981;213:1030-2.

22 McKenna JJ. The potential benefits of infant-parent co-sleeping in relation to SIDS prevention: overview and critique of epidemiological bed sharing studies. In: Rognum TO, ed. Sudden infant death syndrome, new trends in the nineties. Oslo: Scandinavian University Press, 1995: $256-65$

23 Johnson P, Andrews D. Thermoregulation and cardiorespiratory control during the perinatal period. In: Beckman RC, Brouillette RT, Hunt CE, eds. Respiratory control disorders in infants and children. Baltimore: Williams and Wilkins, 1992: 76-88.

24 Cooper KE, Veale W. Effects of temperature on breathing. In: Cherniack NS, Widdicombe JG, eds. The respiratory system. Baltimore: Williams and Wilkins, 1986: 691-702.

25 Haraguchi S, Fung RQ, Sasaki CT. Effects of hyperthermia on the laryngeal closure reflex implications in the sudden death syndrome. Ann Otol Rhinol Laryngol 1983;92:24-8.

26 Stevens LH. Sudden unexplained death in infancy. Am $\mathcal{F} D$ is Child 1965;110:243-7.

27 Stanton AN. Sudden infant death. Overheating and cot death. Lancet 1984;ii: 1199-201.

28 Fleming PJ, Levine MR, Azaz Y, et al. Interactions between thermoregulation and the control of respiration in infants: possible relationship to sudden infant death. Acta Paediatr 1993;389(suppl):S57-9.

29 Brouillette RT. Assessing cardiopulmonary functions during sleep in infants and children. In: Beckman RC, Brouillette RT, Hunt CE, eds. Respiratory control disorders in infants and children. Baltimore: Williams and Wilkins, 1992: 125-41.

30 Azaz Y, Fleming PJ, Levine M, McCabe R, Stewart A, Johnson $\mathrm{P}$. The relationship between environmental temperature, metabolic rate, sleep state, and evaporative water loss in infants from birth to three months. Pediatr Res 1992;4:417-23.

31 Stothers JK. Head insulation and heat loss in the newborn. Arch Dis Child 1981;56:530-4

32 Wailoo MP, Petersen SA, Whittaker H, Goodenough P. The thermal environment in which 3-4 months old infants sleep at home. Arch Dis Child 1989;64:600-4.

33 Bruck K. Temperature regulation in the newborn infant. Biol Neonate 1961;3:65-119.

34 Mestyan J, Jarai I, Fekete $M$. The significance of facial skin temperature in the chemical heat regulation of premature infants. Biol Neonate 1964;7:243-54

35 Chiodini BA, Thatch BT. Impaired ventilation in infants sleeping facedown: potential significance for sudden infant death syndrome. $\mathcal{F}$ Pediatr 1993;5:686-91.

36 Markestad T, Skadberg B, Hordvik E, Morild I, Irgens L. Sleeping position and sudden infant death syndrome (SIDS): effect of an intervention programme to avoid prone sleeping. Acta Pcediatr 1995;84:375-8

37 Malcolm G, Cohen G, Henderson-Smart D. Carbon dioxide concentrations in the environment of sleeping infants. F Paediatr Child Health 1994;30:45-9.

38 Skadberg BT, Oterhals A, Finborud K, Markestad T. CO rebreathing: a possible contributory factor to some cases of sudden infant death? Acta Paediatr 1995;84:988-95. 